\title{
CUANDO LA FE Y EL PODER MUEVEN DINERO; TRIQUIÑUELAS DEL TRIBUNAL DE CRUZADA EN INDIAS ${ }^{1}$
}

\author{
Dr. José Antonio Benito Rodriguez
}

En nuestro intento de aprehender la vida toda del pasado americano, hemos de buscar atalayas que dilaten nuestra pupila para esclarecer la tupida red de acontecimientos o encuentros protagonizados por la persona humana, bien sea a título individual o institucional. Junto a las grandes realidades administrativas como puede ser la Real Audiencia o el Episcopado funcionaron otras menores, como el Tribunal de Cruzada, cuyos miembros y actividades se entrelazan en el complejo entramado del organigrama de la sociedad colonial.

\section{INTRODUCCIÓN}

La Bula de Cruzada era un documento pontificio por el que se concedian favores (privilegios, gracias) espirituales destinados a quienes -previas disposiciones espiritualesse comprometían a participar en la lucha contra los infieles, tanto de forma directa (en la guerra) como indirecta (a través de la limosna); con el transcurrir del tiempo, su doble finalidad espiritual y hacendística, se convertirá en una mèra renta estatal, aunque conservara su secular motivación religiosa o su envoltorio espiritual. Pot tanto, la Bula sólo era comprensible desde la interdependencia de aspectos que hoy son independientes $y$ autónomas, tales como Iglesia y Estado, fe y dinero...pero que antaño iban a la par, cuando no se confundían, en una curiosa relación fe-hacienda, segủn la cual, a mayor vitalidad espiritualidad y vivencia de la fe, mayor eta el ingreso proporcionado por la limosna y viceversa.

Para comprender en profundidad la Bula, hay que arrancar desde su origen, desde las primeras concesiones pontificias para España, su papel en la Reconquista, y seguir de cerca su evolución histórica, desde la depuración conciliar de Trento, hasta llegar con su evolución posterior hasta el S.XIX, enriquecida ya con siete tesoros:

1. Indulgencias. 2. Oficios litúrgicos y sepultura eclesiástica. 3. Confesión y conmutación de votos. 4. Dispensas de irregularidad e impedimentos matrimoniales. 5.

\footnotetext{
'Cominicación peesentada en las Jornadas de Historia Colonal celebrudas en Ocucajc, 2000, organizadas por la PUCP
} 


\section{Dr. José Antonio Benito Rodriguez}

Composición de bienes mal adquiridos. 6. Abstinencia y ayuno. 7. Oratorios privados.

El Consejo de Cruzada, como institución suprema en España, y el Tribunal de Cruzada, como subdelegación del Consejo en Indias, constituyeron la columna vertebral de toda la organización relativa a la Bula de Cruzada en América.

Desgraciadamente, falta una monografía sólida que nos muestre la génesis, estructura, miembros y actividades de estas instituciones ${ }^{2}$. Si algo concluimos en nuestro estudio es que la febril campaña de tres siglos de predicación tras predicación se debió a los latidos permanentes de sendos organismos. A través de un inmenso océano de leyes, sermones, instrucciones o cartas, nos acercamos a un mundo dinámico de lo más variopinto. Nos encontramos en él, desde tesoreros embargados a piadosos predicadores que hacen apología la Bula, o bien desde ingenuos y fervientes fieles que toman la bula, a socarrones cronistas que se admiran de las "industrias" de tesoreros para llenar el Arca de la Hacienda. Un rico abanico de manifestaciones que nos permitirán obtener determinadas conclusiones sobre el funcionamiento de estos organismos, que es lo que nos interesa.

Por su doble jurisdicción, eclesiástica (es concesión papal) y real (la limosna va destinada a sufragat los gastos de las guerras de la Corona contra los infieles), el Consejo y Tribunal de Cruzada deben mantener un equilibrio inestable entre el poder politico, representado en los virreyes, y el religioso, encarnado en los obispos y los superiores de órdenes religiosas. Si por su actividad hacendística de recaudar la limosna estaban en relación directa con el Tribunal de Cuentas, por los fueros recibidos como privilegios de Cruzada se enfrentaron con frecuencia a las Audiencias y los ministros de Justicias. Para hacer llegar las bulas a los lugares más recónditos acudían a los chasquis y a cuantas personas desempeñaban un papel representativo en la sociedad y viajase con frecuencia. En numerosas ocasiones, sobre todo en los primeros momentos en los que se van

\footnotetext{
2Anow los rabajos publicados sobre el asunta que nos ocupa.

1993 "La imprenta del Monasterio de Prado y la Bula de Cruzada de In dias" Los castellanes y leoneses en la empresa de Las Indras juntu de Castilla y León, Valladolidpp, 109-132.

1994 "La Bula de Cruzada: De la Reconqusta a su implancaciōn en fndias" El Reano de Granadá y el Nucu Mando. Diputación Drovincial, Granadu, I, pp, $533-546$

1996a La Bula de Cruzada en Indras Universidad de Valladolid, Valladolid pp.537 (Tesis docioral en microfickas)

1996 b "La modélica gestión de Gonzalo de la Maza, primer contador de Cruzada en Perú", Missionalia Huspainiosa- Hispana Sarna Madrid, CS.1.C.Vol.47, n97,199-230.

1996 " "Andrés de Zabala, un vasco en la Contaduría de Cruzada en Lima". Alavay Améría (Universidad del Pais Vasco. Vitóna, Pp. 307322

1996 "Historia de la Bula de la Cruzada en Indias" Renista de Estudios Historico-furtidios, Ediciones Universitarias de Valparaiso (Chile), XVIII,pp.71-102

1997 "La Bula de Cruzada y los naturales de Indias". IV Congreso Internacional de Elmobistora Ponoficia Untversidad Católica del Peru, Fơndo Editorial, Lima III, pp. 29-55. $169-90$

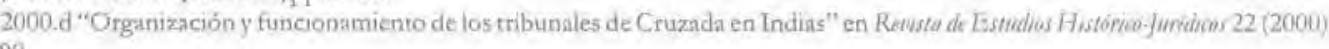


CUANDO LA FE $Y$ EL PODER MUEVEN DINERO:

TRIQUIÑUELAS DEL TRIBUNAL. DE CRUZADA EN INDIAS

asentando los Tribunales, deben valerse de los funcionarios civiles, como Oficiales Reales, y de los ministros eclesiásticos, obispos y miembros del cabildo catedralicio.

Lógicamente, en virtud de su complejidad y de la amplia gama de atribuciones, por el tribunal desfilaban asuntos y situaciones de los más dispares. Desde la preparación de la entrada del Virrey Villalonga, el primera del Nuevo Reino de Granada, hasta la reclamación del notario de Cruzada, Juan Tamayo, cargado de hijos, con mucho trabajo y sin ningún sueldo. Desde el juicio a un negro por el crimen perpetrado contra un indio", esclavo de un alguacil de Cruzada, hasta la defensa de Cartagena ante los ataques de Jos corsarios. Unas veces tendrán que frenar las "tomas" de dinero de los virreyes ante lo que éstos consideraban como "urgencias", y otras será el propio Tribunal quien hará frente a gastos derivados de necesidades civiles, como la defensa de Cartagena. Le vemos derrochar ingenio para calmar su escrupulosa conciencia convocando Juntas de teólogos para ver si se podían "reusar" bulas sobradas de una predicación por el fervor de la gente, y al mismo tiempo contemplar que hasta los mismos religiosos se oponían por considerar que las concesiones no eran legitimas. Si uno de sus ministros, el tesorero de Cruzada en Perú, Lesmes de Espinosa, a comienzos del S.XVII, se inclinaba por seguir imprimiendo las bulas en España para que los indios las considerasen como un regalo venido "como del Cielo", al Tribunal llegará la denuncia de que en Santa Fe los escultores las utilizaban como pasta de papel-cartón para sus modelos.

El P. Bernabé Cobo, al hablar de la "fundación de Lima", se refiere al tribunal de la Santa Cruzada- "para las cosas tocantes a la expedición de la santa bula y privilegios de ella"--como "de los más antiguos que se han fundado en esta república". Se remonta al 21 de junio de 1537 como fecha de recibimiento del primer tesorero en el bachiller Miguel Rodriguez de Cantalapiedra. Sin embargo, añade que "el tribunal presente, con la autoridad, poder y ministros que tiene, se instituyó el año 1604, a mediados de agosto." En un primer momento los subdelegados comisarios fueron los arzobispo y obispos y sus provisores y vicarios generales, y por muerte de ellos, las dignidades o canónigos más antiguos; la cobranza dependía de los virreyes y Oficiales Reales. En 1600 el Consejo General de Cruzada proveyó que la subedelegación general de la provincia del Perú, Tierra Firme y Chile, se administrase por persona en exclusiva a la que se adjunta un contador, encargado de la administración, expedición y negocios de la Santa Cruzada. "La jurisdicción de este tribunal consiste en haber subdelegado el comisario general, plenamente y sin limitación alguna toda la suya, como la tiene de SS al comisario de él ${ }^{34}$.

AGI (Archivo General de Indias), Indiferente, 2865.2. Este indio, sastrt de profesión, Damado Domingo Nlonso, era cnadio del aiguacil de Cruzada José de Buendia. Se otdenó a la Real Audiencia volvjese a formar de nuevo la competencia reguhar. uras el proceso inetado y promovido desded Tribunal de Cruzada de Lima.

'Obras det P. Bemabé Cnfo II, Capitulo XIX, p.402, BAE92, Madrid 1964 


\section{ORGANIGRAMA DEL PROCESO COMPLETO}

de concesión, publicación, predicación y administración de la Bula
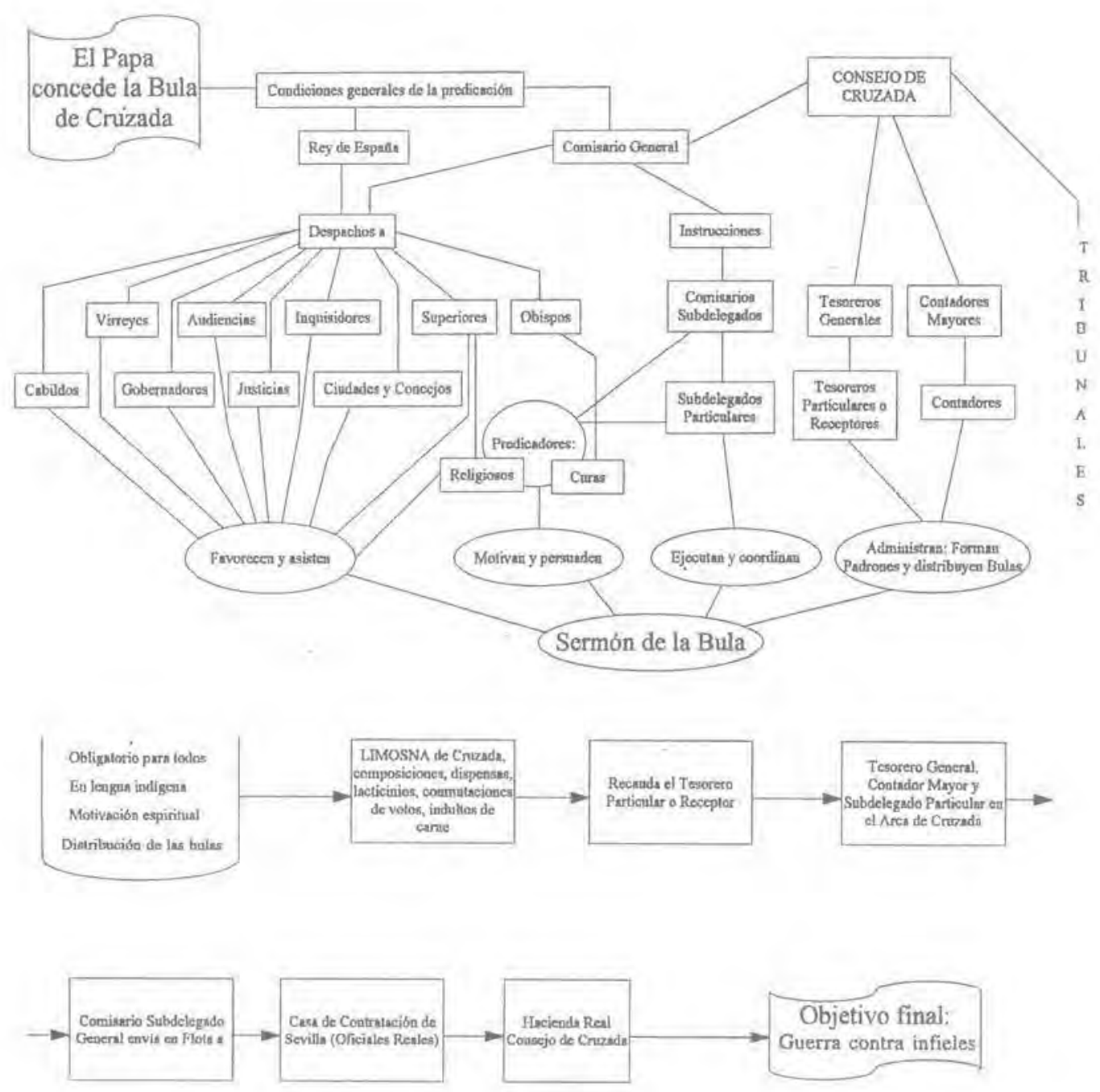
CUANDO LA FE $Y$ EL. PODER MUEVEN DINERO;

TRIQUINUUELAS DEL TRIBUNAL DE CRUZADA EN INDIAS

Señala por último los ministros que tiene: comisario con un salario de mil pesos ensayados, un asesor (oidor de la Real Audiencia, con 250 pesos), contador con 3.000, fiscal con 250, secretario (sin más salario que sus derechos), alguacil (uno de corte, con 100 pesos corrientes de a 9 reales), portero (100 pesos), y un solicitador fiscal (con otros cien). "Todos estos salatios están consignados en la expedición de la Cruzada. Tesorero lo es el que mejor postura bace",

\section{FUNDACIÓN Y ESTABLECIMIENTO EN INDIAS}

No se sabe con certeza la fecha exacta de la fundación del tribunal ${ }^{5}$. Hasta su creación, el Consejo de Cruzada nombraba desde España comisarios subdelegados, contadores y tesoreros que se ocupaban de desempeñar las funciones relativas a la bula en Indias. Los nombres y años de los primeros funcionarios de los que tenemos noticia son los siguientes:

- Fray Gabriel de Acuña, Comisario en 1511, en la isla de La Española.

- Hernando Vázquez, Tesorero hacia 1512, en La Española.

- Juan de Velasco, alguacil de Cruzada hacia 1512, en La Española.

- Francisco de Medina, tesoreroen 1516, en las Antillas.

- Pedro Albornoz, Contador hacia 1530, en las Antillas y en México.

Desde 1530 a 1573 los subdelegados fueron casi siempre los prelados diocesanos. En 1573, a raiz de la primera concesión pontificia de la Bula a Indias, se firmó el primer asiento con los tesoreros generales Diego Diaz Becerril, Juan Alonso Medina y Francisco Martínez López. La segunda concesión se desglosó en los dos virreinatos de Nueva España y Perú, concertando el asiento con Luis Núñez y Miguel Sảnchez Parra, respectivamente, Fue en México donde se nombró el primer comisario en la persorra de Sancho Sánchez de Miñón.

El considerable volumen de actividades desplegadas en la publicación y predicación, así como los buenos frutos recogidos en la administración de la Bula, aconsejó el nombramiento de otro comisario y contador para Perú en 1600. Ello dio a pie al Consejo de Cruzada al establecimiento de Tribunales delegados en México y Lima en un primer momento, y posteriormente en todos los lugares que contaban con Real Audiencia.

${ }^{5}$ T. SZASDI LEON-BORJA "La introducción de la Bula de la Santa Cruzada en el Nuevo Mundo (1509-1525)" GMaderyes de. Historia $\mathrm{N}^{\circ} 10$ del Instituto del Dercchor de las Ideas Polícas, Córdoba (Argentuna) 200 pp $113-149$. Aduce coma primera fecha uny Keni Cédula al Gobernador de Ias Indias en relacióo con los bienes de Fern.ando de Monroy el 27 de noviembre de 1503

"AGS (Archive General de Simancas), CCI (Contaduria de Cruzada de indias), 573. 


\section{Dr, Josê Antonio Benito Rodríguez}

La ley primera del apartado dedicado a Cruzada de la Recopilacion de Leyes de Indias asílo recoge:

"Por cuanto para la buena administración de la Bula, que se predica y publica en las provincias de nuestras Indias ha parecido convenir, que en los lugares principales haya un Tribunal formado, para que en él nuestros súbditos y vasallos tengan mejor, más cómodo y cercano recurso donde acudir en apelación con las causas que hubiere y se sentenciaren por los Jueces Subdelegados particulares de aquel distrito y jurisdicción" ".

Las primeras noticias sobre el tribunal peruano nos las ofrece M. Mendiburu, quien dice - sin precisar la fecha, pero antes de 1581- que el tribunal de Perú fue fundado por el virrey D. Francisco de Toledo", pero que "se organizó de nuevo en dicho año $\left(1604^{\prime}\right)$ [...] siendo comisario delegado el arcediano doctor Juan Velázquez ${ }^{310}$. Parece ser que de esta obra tomó sus datos Domingo Angulo, cuando dice:

"Por esta época (año 1546) aún no se había regularizado en estos reinos la publicación de la Bula, y los encargados de predicarla dependían directamente de la Comisaria General de España. Sólo en 1604 se vino a organizar y establecer definitivamente en el Perú el Tribunal de Cruzada, siendo su primer Contador D. Gonzalo de la Maza [.... Funcionaba en la Calle de Santo Toribio, casa de las bulas" "n.

De la crónica de Fray Diego de Córdoba ${ }^{\mathrm{i} 2}$ se desprende también que la fundación primera seria la de Lima en 1603-4.:

.."El (Tribunal) de la Santa Cruzada se fundó el año de 1603 para todas las cosas de la expedición de la bula y privilegios de ella. Está el Tribunal en casa del Comisario General, que de ordinario es una Dignidad o Canónigo de la Santa Iglesia Catedral de Lima, con mil pesos ensayados de Renta, consignados en la expedición de la bula. Tiene un asesor que es siempre es oidor de la Real Audiencia por cédula de Su Majestad y con 250 p de salario; un contador con 3.000 p ensayados y todos estos salarios consignados en la expedición de la Bula. Tiene otros muchos oficiales y ministros menores con sus salarios librados en gastos de Estrados. El primer comisario de Cruzada que tuvo este Tribunal fue el Doctor

Libro 1, Tirulo 20, Ley 1

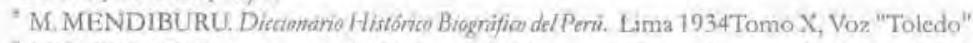

'AGS, CCI, 572. Por una carta del Tribunal de Lima, en 1654, se da como fundación del Tribunal de Cruzada de Tima, ti, año 1600 , y que se han anotado las cuentas de 12 predicaciones correspondientes a la fecha comprendida entre $1602-1626$,

"M. MENDIBURU,: Diccóntario Histórizo Bingráfico del Perí. Lima 1934. Tomo XI, p,278.

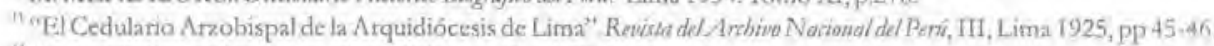

"Teatra de ta Santu Iglesia Muropolitrana ide los Reyes. Lima 1650, p.12. 


\section{CUANDO LA FE Y EL PODER MUEVEN DINERO: TRIQUIÑUELAS DEL TRIBUNAL. DE CRUZADA EN INDIAS}

\section{Juan Velázquez, Arcediano dela Iglesia de Lima",}

Posteriormente, por una Real Cédula, dada en El Escorial el 16 de mayo de $1609^{14}$, se ordenaba la formación de tribunales "de Comisario Subdelegado" en los partidos que contasen con Audiencia Real. Estos son: México, Nueva Galicia, Guatemala, Santo Domingo, Los Reyes, Santa Fe en el Nuevo Reino de Granada, Quito, Santiago de Chile, La Plata en la provincia de Charcas y Manila en Filipinas.

En Santiago de Chile, recibieron los despachos para fundar el tribunal en 1611, al mismo tiempo que se ordenaba que no se sacase dinero de las Cajas de Comunidad para que los indios pobres e impedidos obtuviesen la bula como había sido prescrito por el Virrey para todo el Perí y territotios dependientes ${ }^{13}$.

A su vez, el tesorero de Cruzada de Santa Fe, Jerónimo de León, nos describe los primeros momentos del Tribunal de Cruzada en Santa $\mathrm{Fe}^{16}$, Comienza por indicarnos los cargos existentes en la fundación: subdelegado, asesor, contador y fiscal. La primera limosna registrada fue de 5.489 pesos de dispensaciones. A continuación, nos ofrece detalles del adorno de la sala con dosel, silla de terciopelo ${ }^{17}$ y campanilla de plata, comprados con las limosnas de las condenaciones del propio organismo. Señala además cómo se nombró notario a Alonso Rodríguez y contador a Juan de la Serna, y se solicitó el goce de las preeminencias propias de los ministros de Cruzada, asi como de los mismos salarios que los miembros del tribunal de Lima. Los permanentes problemas con el territorio de Popayán, ya se suscitaron también con este motivo, por estar parte de él sujeto en lo temporal a la Real Audiencia de Quito y parte a la del Reino de Nueva Granada, de tal manera que en la quinta predicación no quisieron recibir las bulas de Popayán, puesto que se habian de enviar desde Quito. Parece ser, que en 1619, con las mismas facultades que el de Lima y México, quedó asentado el tribunal en Santa Fe como lo pone de manifiesto el tribunal de Lima en carta del año $1654^{18}$.

Desde el primer momento, y en virtud de su misión social, los tribunales se convertían en cajas de resonancia de la vida cotidiana de las poblaciones, tal como puede comprobarse en un buen número de documentos. Uno de los más significativos, es la carta dirigida en 1591 por el presidente de la Audiencia del $N^{\circ} R^{\circ}$ de Granada el Antonio González Aláez, al Comisario General Francisco de Ávila. En ella se recogen asuntos

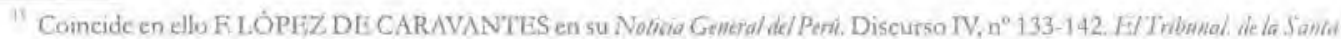

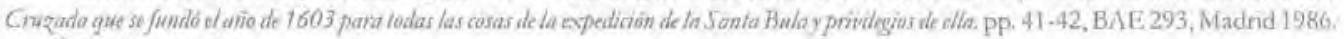

AGS, CCI, 578.

"AGS, CCI, 573, Santiago de Chile, 1611 .

in $\mathrm{AGS}, \mathrm{CCI}, 573.23 .6 .1612$

"AGS, CCI, 573. En otra carta de la misma fecha se nos derallan la colocación de los miembros det Tribunal siturda cn las. Casas Reales: "en una sala bien aderezada. A la cabecera de un bufece, con dos sillas iguales, se ponen el comisario (a la mano derecha) y el asesor; en dos sillas laterales el fiscal y el Oficial Real que hace de Contadot; y, por ultimo, en un banquilio, el norario".

"AGS, CCl, 573 .
} 


\section{Dr. José Antonio Benito Rodriguez}

fundamentales de la vida cotidiana: el papel de los Corregidores de indios como defensores de los naturales de Indias, el aderezo de la Iglesia para poder celebrar "en ella los divinos oficios con la decencia que se requiere [...] y con mucha suavidad se ha pedido el servicio gracioso (la Bula) y compuéstose algunas encomiendas",

\section{MISIÓNYATRIBUCIONES}

Las competencias específicas de los tribunales quedan recogidas en la Real Cédula, de Felipe III, del 16 de mayo de $1609^{20}$, y que aparece en la mayoría de los cedularios y recopilaciones por ser "la llave" ${ }^{\text {21 }}$ de toda la legislación sobre la materia:

"Y en los dichos Tribunales y por el Subdelegado General y Oidor se verán, sentenciarán y determinarán todos los pleitos, negocios y causas que hubiere en sus distritos y partidos, así en lo tocante a la administración y cobranza de la Cruzada como los que fueren entre partes, y ante ellos ocurrieren de los otros subdelegados de su distrito en grado de apelación."

Sus sentencias se podian recurrir ante el Comisatio General y Consejo de Cruzada $^{22}$. Si no había acuerdo en la votaciỏn, el Comisario Subdelegado debía notificarlo al Virrey, como presidente de la Audiencia, para que nombrase otro oidor que

"asista a los negocios, no se conformando y hagan sentencia otorgando a las partes las apelaciones que ante ellos interpusieran para ante el Comisario General y Consejo de Cruzada, y no para ante el Tribunal, ni juez alguno, sin que por vía de fuerza, ni por otro algún modo se puedan llevar las causas a las Audiencias Reales, ni introducirse en ellas en ninguna forma, porque en cuanto esto las inhibimos" ${ }^{23}$.

Las reuniones o "audiencias" debían celebrarse en dias y horas no coincidentes con las de la Real Audiencia ${ }^{24}$. Y asi se ordena que se efectúen tres tardes de cada semana ${ }^{25}$ $y$ "si hubiere costumbre ${ }^{26}$ que sean menos, se guarde la costumbre". M. J. Ayala recoge una Real Cédula, de 1714, para La Habana en la que se manda al Contador evite todo tipo de enfrentamientos con el Subdelegado asistiendo con él al teconocimiento de cuentas

\footnotetext{
"AGS, CCI, 586

"AGS, CCI. 576, Ei Escorial 16.4.1609. También en: BNM, Mans. 2989, 517 . S.Lorenzn 16-5-1609, S.Lorenzo. Tribunal de Cruzada en las ciudades con Audiencia Real. p, 589

"Según expresión de J de SOLORZANO: Polinira Indiana. Madrid, 1930, Libro IV, Capiulo XXV, n. 15

${ }^{22}$ Según expresión de J. de SOLORZANO: Polinica Indiana. Madrid, 1930. Libro IV, Capitula XXV, n. I6

"AYALA, MJ J Nolas a la Recopilación de Indias. Origen e bisloria illustrada de las Leyer de Indias Estudio de f Manzano Manzano. Cultura Hispánica, Madrid, 1945, Libro 1, Tíulo 20, Ley 1. Real Cédula de 16.5.1609.

" Thidem. Libro 1, Titulo 20, Leyes 2 y 12.

"I de SOLORZANO: Pollitio Indiama. Madrid, 1930. Libro IV. Capitula XXV, n. 36.

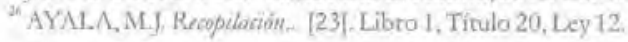


CUANDO LA FE Y EL PODER MUEVEN DINERO:

TRIQUIÑUELAS DEL. TRIBUNAL DE CRUZADA EN INDIAS

Mapa de la recaudación de la limosna de Cruzada

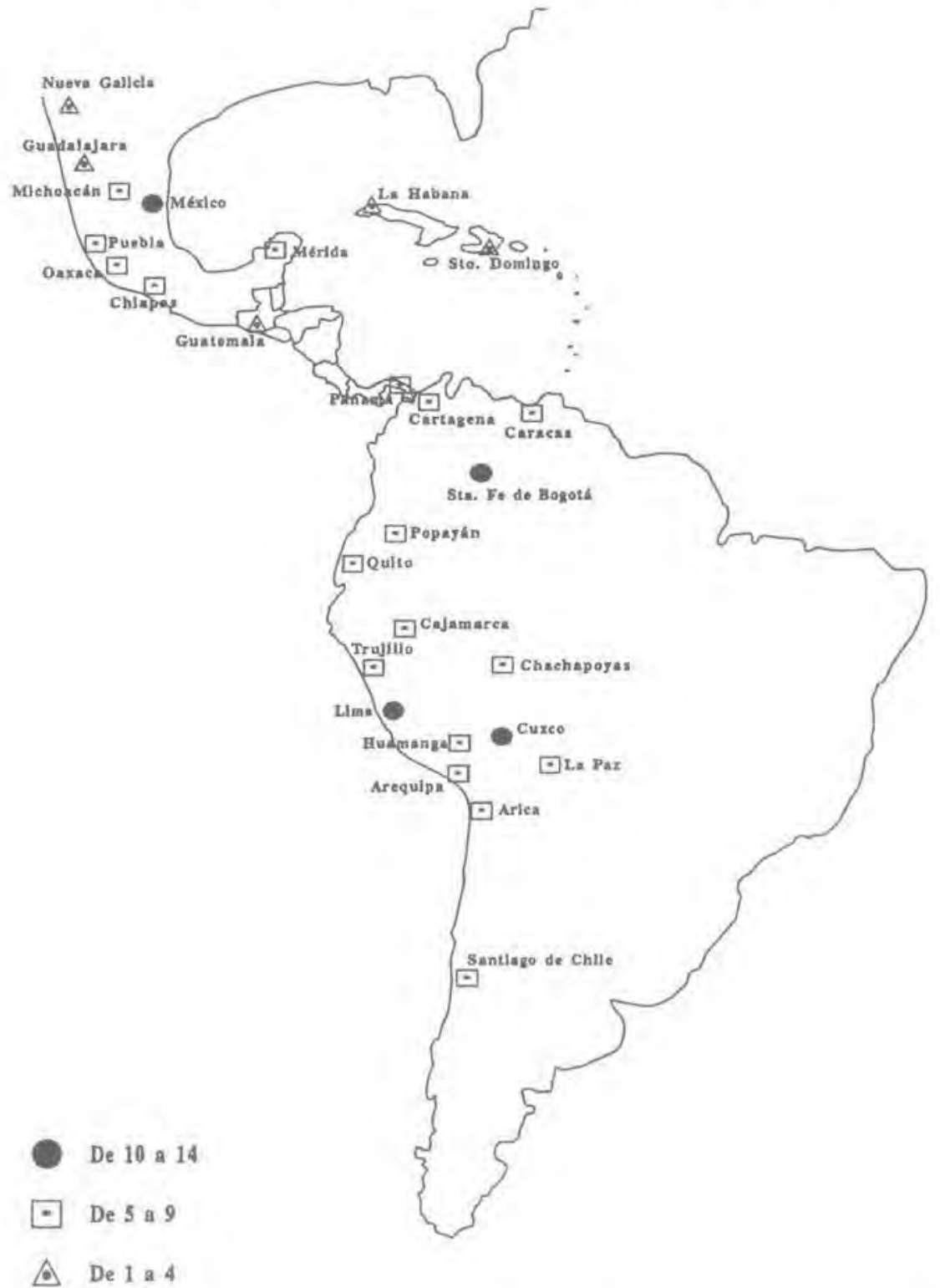

Localidades con Cuentas y Números de Concesiones Documentadas en el Archivo de Simancas Cada concesión comprendía 6 predicaciones de 12 en total 


\section{Dr. Josê Antonio Benito Rodriguez}

los lunes y jueves de cada semana, desde las 9 a las 11 de la mañana, y en los siguientes en caso de ser festivos ${ }^{27}$.

Sus atribuciones específicas van encaminadas a cuidar de que lo que procediere de la Cruzada y composiciones, se recoja en las Cajas Reales de su distrito y se envie en cuenta aparte con el resto de la Hacienda Real en los mismos navios y flotas, dirigido al Comisario y Consejo de Cruzada "con relación distinta y particular de lo que viniere y de qué años, asientos y predicaciones fuere, y lo que restare debiendo y el estado en que queda la cobranza y seguridad de ella". En consecuencia y para cumplir con esta misión, tanto los subdelegados como los contadores debian poseer un libro de cuentas del dinero recaudado. Por último, se ordena a todas las autoridades civiles que "hagan guardar, cumplir y ejecutar las sentencias, mandamientos y autos" que el Tribunal diere. Pese a todo, no siempre habia claridad meridiana a la hora de actuar. Por ejemplo, el Tribunal de Santa Fe, en 1661, nos manifiesta sus dudas por no haber ordenanzas y se pide copia de las mismas al Consejo y que se remitan con Real Cédula ${ }^{28}$.

Al margen de las misiones comunes y ordinarias, sin embargo, el tribunal tenía funciones específicas para determinados casos, como el que nos da a conocer Jerónimo Valera, subdelegado en Santa Fe, a propósito de una consulta sobre si las ciudades debian salir en forma de acompañamiento la víspera de la publicación de la Bula. En la misma exponia que la auténtica obligación de los ministros de Cruzada, particularmente del Subdelegado, es:

"conservar el lustre del Tribunal de la Cruzada para la pública veneración en el estado que SM (Dios le guarde) quiere por sus Reales órdenes [...] y porque la pompa de la solemnidad persuade a la veneración y devoción de la SB principalmente en estas partes donde el común es nuevo plantel en la mies de la Iglesia por componerse de indios, negros y mulatos que aún no pierden de vista la gentilidad_y a éstos mueve más la solemnidad y pompa externa que con debido culto ven dan los católicos de la primer nobleza que lo interior de su veneración pues ésta sola se les comunica por las exterioridades a que parece atendió SM en la expedición de la Real Cédula citada"

Con todo, y sin infravalorar la importancia dada al ornato y ceremonia externa, lo "primero y principal cuidado del Subdelegado y Tribunal de Cruzada [...] ha sido que las limosnas estén corrientes y los enteros prontos ${ }^{13^{30}}$. La información nos la

\footnotetext{
"M.J. AYALA: Dictionario de Gobieno y Legislación de Indias. Essudio de M.M.del Vas Mingo. Cultura Hispánica, Madrud, 1989 Voces: "Buias", "Bulas de la Sanra Cruzada" y "Cruzada"

AGS, CCl, 572.

"AGS, CCI, 568.18,12.1694. Tal como figura en la Real Cédula de 21.3.1625, que dio origen a la ley 8, tículo 20, fibra. I de bt Recopilación ...

": "Enteros"; Entregas de dinems.
} 


\section{CUANDO LA FE Y EL PODER MUEVEN DINERO: TRIQUIÑUELAS DEL TRIBUNAL DE CRUZADA EN INDIAS}

proporcionan los responsables de la Provincia de S. Francisco ${ }^{3 t}$ en Nueva Galicia. Ciertamente, tiene razón el Tribunal de México cuando al referirse a los enteros en las reales arcas de todas las tesorerias de Nueva España dice que "es necesaria una frequentísima ocupación",

Los Comisarios Subdelegados, nombrados por el Comisario General desde la Peninsula, se encargaban de crear los tribunales que, donde había Audiencia Real, constaban del oidor más antiguo, el fiscal civil, un contador, un secretario y otros ministros necesarios con salario. A estos ministros se subordinaban otros comisatios particulares en las provincias y ciudades cabezas de partido, con la responsabilidad de la predicación y administración de la Bula en su jurisdicción territorial. Para ello, nombraban tesoreros encargados de recaudar la limosna que cada año se enviaba a España. En ocasiones, este cargo se convertía en asidero para buscar futuros trabajos, como vemos que intentó en 1789, el empleado en la venta de bulas, Salvador Díaz de Losada, el cual solicitó al Tribunal que recomendasen sus méritos ante el Comisario General ${ }^{33}$.

La actividad de los miembros del Tribunal fue controlada periódicamente por las visitas, Destacaron por su eficiencia las de H. Arias Ugarte (1611) ${ }^{34}$, Martín Carrillo $(1627)^{35}$ y Juan de Ocón (1650), en Perú ${ }^{36}$. En el virreinato de Nueva España, sobresalieron las realizadas por J. Palafox (1641) y Fr. Marcos Ramírez de Prado (1646). Una de las misiones del Visitador era solucionar judicialmente todos los problemas surgidos entre los ministros del Tribunal. Así lo manifiesta la Real Cédula, de 5.10.1647, enviada a Panamá como resultado de la visita efectuada por el visitador Ramírez del Prado:

\footnotetext{
"AGS, CCI, 583. Guadalajara, 2.4.1666.

" AGS, CCI, 589. México, 7.1.1679. Se da cuenta de cómo los abispacios dependjentes tienen ajustadas sus cuentas y cómo. Honduras, dependiente de S.Domingo no to ha hecho. Lis cuentas pendientes son muy numerosas, tal como podemos ver en el Informe de Doninge de Olarte, 10.12.1711, en su praje o Indias, basado en los Lubros de la Contaduria Mayor de la SC del cargo del Sr. D. Andrés de Villamayor. Cuentas que ban penido de todas has partidos del Reino del Perá y Tierra Firme, en el que partidos como Barranca y Trinidad llevaban sin tendir cuentas 55 predicaciones, durante 110 años; otras, como Cumanti, no habian e fectuado ainguna todavja.

"AGN, México, 214. Año 1789.

"AGS, CCI, 573.

${ }^{3} \mathrm{AGS}, \mathrm{CCI}, 556$.

${ }^{4} \mathrm{AGS}, \mathrm{CC}, 561$. Consulta y cêdula al arzobispo Juan Alonsó Ocón en 1653 para que el uibunal de Lama le hiciese dar 4000 pesos por la visita al rribunal de Charcas. AGS, CCI, 572 . Real Cédula para agradecer a Juan Alonso Ocón su visita a Jos cribunales Perú.

AGS, CCI, 576 . Real Cédula de 1.2 .1648 con merced de 3000 ducados de ayuda de costa en las penas pecunsarias y condenaciones procedidas de la visita que hacia al Trabunal de Cruaada de México, M. Ramirez del Prado
} 
"Representado el subdelegado de Panamá que provisto su tesorero Don Francisco de Benavides por alcalde ordinario, debiendo a aquel ramo 1.500 pesos puso algunos embarazos el Presidente a su cobro, mandando al alguacil mayor no cumpliese las órdenes de aquel juzgado sin preceder la suya, que aunque la dio, fue con limitación de tiempo, y entrometiéndose en la jurisdicción del subdelegado: le previno SM evite rencillas y dejase libre la jurisdicción de dicho Tribunal, y mediante deberse reputar por Hacienda Real el procedido de la Bula, si ésta no tuviese alguaciles que ejecutasen sus mandamientos, ni impidiese hacerlo el de la Audiencia, ${ }^{, 38}$.

\section{FUEROSY PRIVILEGIOS}

Fueron numerosas las Reales Cédulas que dieron origen a la ley 6 de la Recopilación de Indias, por la que se mandaba a todas las autoridades civiles que "honren y favorezcan a los Ministros y personas, que intervinieren en la administración y cobranza" de la Bula. La Ley 19 especificaba que las autoridades "favorezcan y honren a los tesoreros de la Cruzada, haciéndoles en todo buen tratamiento y que se les guarden y hagan guardar todas las preeminencias que se les debieren y hubieren guardado por razón de los dichos oficios". Un aspecto concreto de los privilegios que se les otorgaban nos lo revela el Comisario de Panamá, Luis Guerra de Ocaña, al reclamar que "se le dé plato de la carnicería y de los demás mantenimientos de la Tierra como a los demás ministros superiores por su dinero"3\%. Quizá para frenar su desbordada ansia de privilegios y exenciones, el 2 de mayo de 1602, se enviaba una Real Cédula a Lima, recogida por J. de Solórzano, en la que se ordenaba que "los ministros y oficiales de Cruzada no son exentos de alcabala" ${ }^{\text {,40 }}$.

Particular interés reviste el fuero o "inhibición" de que disfrutaban sus ministros. Según esto, ningún tribunal, ni siquiera el de la Audiencia, podia intervenir en sus asuntos propios ${ }^{41}$. No es de extrañar que algunos sujetos acudiesen al Tribunal de Cruzada para eludir algún proceso judicial ${ }^{12}$. Asi lo manifestaba el viștador $M$. Ramírez

\footnotetext{
"M.J. AYAL. А: Ducrmyarso, [27], Va:"Cruzada, n.8

MGI, Indiferente, 28665,1

"Politica.. Libro IV, Capiculo XXV, n.50)

"AGS, CCI, 588. RC de inhibición de las cosas de Cruzada para los justicias de Perí y Tierta Furme; 12.6.158.3 para que na se entrometan en lo concerniente a la Bula.

"1. GONI: Historia de la Bula de Cruqada en Esponãa. Seminario Mayor, Vitatia 1958, llega a decir para los das anteriores al Concilio de Trento: "Cuando un sacerdote con cura de almas queria eludir la jaeisdicción del ordissario y la obligaeión de la residencia, no tenia más que servir a la Cruzada"
} 


\section{CUANDO LA FE Y EL PODER MUEVEN DINERO: TRIQUINNUELAS DEL TRIBUNAL DE CRUZADA EN INDIAS}

del Prado en sus Ordenanzas, cuando advertia al Subdelegado que cuidara de que los tesoreros "no quieran y soliciten dichos títulos para substraerse de la jurisdicción real y para valerse de sus privilegios de sus derechos reales y competencias con las justicias ordinarias, como se ha reconocido en las residencias y visitas que han hecho antes para servirle mejor en este ministerio",

La ley 5 de la Recopilación, no obstante, era contundente en este sentido: "Que los virreyes, Audiencias y otras Justicias Reales no conozcan de causas tocantes a la Cruzada, subsidio, cuartas y sus cuentas, ni aun por vía de fuerza" ${ }^{\text {th }}$. En caso de competencias jurisdiccionales, J. Solórzano ${ }^{\text {th }}$ recoge una Real Cédula, de 1636, destinada a arbitrar soluciones. Por ella, se ordenaba que se juntasen dos "conjûdices" (conjueces), uno eclesiástico y otro secular, con el Subdelegado, y que decidiera el voto de la mayoría. Sí la discordia persistía aún, la dirimiría una Junta formada por tres miembros: el Virrey o Gobernador, un Oidor y el Subdelegado de Cruzada, ejecutándose lo que resolviese la mayoria, esto es, dos de los convocados ${ }^{46}$.

Pero ya en los primeros años de funcionamiento del tribunal peruano, los oficiales de Cruzada solicitaron al Comisario General exención en lo civil y criminal, de la jurisdicción ordinaria, como en Nueva España, y que sólo los Comisarios Subdelegados pudieran conocer de sus causas, pues "en más de 1.100 leguas (Quito-Asunción del Rio de la Plata y B.Aires) no llegarán a 100 entre tesoreros, notarios, alguaciles y receptores [...] y con ello serán los oficios apetecidos y andarán en personas honradas y ricas ${ }^{3{ }^{47}}$. Y aunque de momento no se respondió afirmativamente a tal solicitud, sin embargo, desde la Peninsula se enviará una Real Cédula, el 11.6.1613 ordenando al virrey del Perú honre y favorezca al Comisario Subdelegado de Cruzada y que en el tratamiento y cortesía le diferencie de los demás capitulares de sus iglesias caso de ser los subdelegados dignidades de ellas ${ }^{48}$. Con la misma fecha, se remitió otra Real Cédula al Virrey de Perú en la que se mandaba que cuando los tesoreros de Cruzada fueren a tratar con él asuntos de

\footnotetext{
"M.j. AYALA: Dicrionano. [27]. Vaz "Cruzada": "Considerando el Rcy que el medio de que bubiese personas a propósiro,-2 abonadas en Indias para servir las resorerias de ella, aumentar su consumo, y recaudar bien su importe, era que gozasen el fuero concedido al de Castilla: mandó, que con los que lo fuesen en aquellos reinos se observase lo que con este [a. $]^{n}, 26,4,1721$, n, 20 y P.

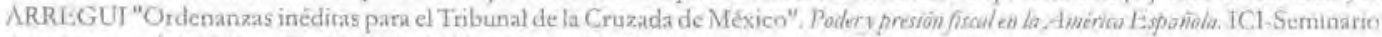
Amencanista de la Eniversidad de Valladolid, 1986, pp.425-55.

"Recapilacion..- [23], Libro 1, Titula 20, Ley 5. La ley recoge las Reales Cedulas de 13.5.1578, 26, 7, 1578, 22,12.1578, 12,6.1583,

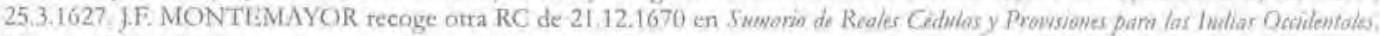
Méxuco, 1867, L.I, T.14;iguaimente, en Nurva Kecopilación de Castilla, 1, 10, 8.

"Politica Indiana. Madrid, 1930. Libro IV, Capitulo XXV,n 19.

"Ibidem Libro IV, Capitulo XXV,rs.19.

" $\mathrm{GS}, \mathrm{CCI}, 578$.

"AGS, CCl, 576 .
} 
sus oficios les diesen el mismo tratamiento que a los Oficiales Reales de la Real Hacienda ${ }^{40}$. Asimismo, en otra Real Cédula dirigida al Virrey de Perú, Marqués de Montesclaros, se le ordenaba honrase y favoreciese a los tesoreros de Cruzada y les guardasen las mismas preeminencias que a los Oficiales Reales, permitiéndoles llevar dos esclavos con armas y se les repartiesen indios de mita como a los oidores, inquisidores, oficiales y otros ministros ${ }^{50}$.

Años más tarde, en 1669 , se enviaba una nueva Real Cédula al virrey y presidentes de Audiencias del Perú con el fin de que respetasen los privilegios de los ministros de la Cruzada y les den la ayuda necesaria para cumplir con su oficio ${ }^{\text {st }}$.

Por lo que respecta a México, Antonio de Villaseñor y Monroy, avisaba en 1701 haber recibido orden del Rey de que no se concediese a los tesoreros de Cruzada el fuero pretendido; pese a que hubiese insistido en ello Luis Miguel de Luyando, tesorero actua ${ }^{32}$. Sin embargo, veinte años más tarde, en 1721 , a consulta del Consejo de Cruzada, fue aprobada por Su Majestad la concesión del fuero de Cruzada a los tesoreros de Indias, igual que lo disfrutaba el tesorero general de los Reinos de Castilla y León ${ }^{53}$. Otros ministros de Cruzada, sin gozar del fuero, disfrutaban en cambio de importantes privilegios, como hemos señalado. En virtud de ellos, el teniente de alguacil mayor de Cruzada de México, Juan Antonio de Osorio, teclama contra el apresamiento de su persona ordenado por el virrey, sin tener en cuenta la función que desempeñaba y las atribuciones propias del Tribunal al que servía ${ }^{54}$. Y es que el teniente alguacil era una víctima de un conflicto de competencias entre el Tribunal de Cruzada y la Audiencia, presidida por el virrey, conflicto en el que la primera autoridad política había tomado partido y actuado sobre la persona del teniente alguacil, cuando de acuerdo a lo legislado sólo en casos "extraordinarios y de gobierno superior, por razón de la quietud pública, en competencias de Tribunales encontrados, se puede interponer al Virrey, usando para remediarlas, de los poderes que tiene, como quien representa la Real Persona ",35.

\footnotetext{
"AGS, CCI, 576.

${ }^{*}$ AGS, CCI, 576. San Lorenzo de El Escorial, 28.6.1613.

"AGI, Indiferente, 430, 41, f:184-5.

${ }^{32}$ AGS, CCl, 578 .

"AGS, CCI, 578.

"AGS, CCI, 578. Carta de 24.4.1733 al Comisario General Juan de Carnargo que concluye de esta manera: "Y que los negocios no paguen las. controversias de los ảnimos". El documento en el que se conserva la carta es el "Testumonio de autos que se siguen en el Tribunal de la SC de Méxuco en la NE sobre que la Real Sala del Crimen remita a él cierta causa criminal que de orden del $5 r$. Virrey se ha fulminado contra el St. Teniente de Aiguacil Mayor de dicho Tribunal por iocarle sus conocimientus en virtud del pavilegio de fuero que goza"

"ISCALONA AgUlRRO, G. de: Gazuphilaciam Regram Perubictum, BNM, Sección "Raros", Madrid, 1775.Il, 32, 9.
} 


\section{CUANDO LA FE Y EL PODER MUEVEN DINERO: TRIQUINUUELAS DEL TRIBUNAL DE CRUZADA EN INDIAS}

Estos fueros y privilegios se potenciaron cuando muy pocas personas aspiraban a ser ministros de Cruzada en el primer tercio del S. XVIII. El Consejo de Indias, sin embargo, pronto a evaluar la repercusión vital del disfrute de fuero y privilegios por parte de los ministros de Cruzada, les marcará como pauta de referencia el buen trato hacia los indios, dado que, como el propio Consejo de Indias denunciaba "hoy corren (los ministros de Cruzada) tan sin dependencia de los virreyes, audiencias y justicias que no hay castigo para ellos" ${ }^{3034}$. Como remedio, el Consejo ordenó que "en los delitos y causas que los Ministros de la Cruzada cometieren contra los indios así civiles como criminales no gocen de la jurisdicción, fueros y exenciones de la Cruzada [.... $]^{\text {"3? }}$.

\section{RELACIÓN CON LAS INSTANCIAS DE GOBIERNO, INSTITUCIONES X TRIBUNALES}

Hemos hablado ya de la doble jurísdicción de los ministros de Cruzada en cuanto que reciben el poder espiritual de una concesión pontificia, por tanto eclesiástica, pero al mismo tiempo, y a todos los efectos, son funcionarios dependientes del monarca. Guardar el equilibrio entre el poder político y religioso, cuando no siempre están delimitados, será extremadamente difícil, produciéndose frecuentes situaciones de armonia, pero también de confrontación. Así, ocasiones hay en las que será el virrey el que apela a los sentimientos religiosos de los prelados y religiosos para que pongan todo su calor en la predicación y administración de la Bula y otras veces -en cambio-en las que serân los mismos prelados o doctrineros quienes apelarán a los sentimientos cristianos de las autoridades civiles para que no decaiga la Bula.

En cada predicación, el Rey, a través del Consejo, enviaba tres tipos de documentos con el fin de proteger y motivar la Bula:

- Patentes para los tesoreros de la Cruzada.

- Cédulas a los virreyes, capitanes generales, presidentes y oidores de Audiencia, gobernadores, corregidores, alcaldes mayores y ordinarios, alguaciles y otros cualesquier jueces y justicias, asi como cédula particular a las Audiencias, concejos, prelados, cabildos catedralicios, provinciales de órdenes religiosas e inquisidores.

- Despachos del Comisario General para los subdelegados gencrales y subdelegados particulares, asi como poderes para los tesoreros y cartas para los cabildos.

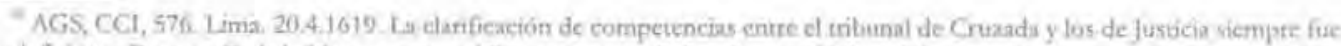
muy deficionte Por ese, G. de la Maza, en carta al Rey, expone su dada sobre si el Tribunal de Gruzada tiene jurisdiceón para privar del ofiçis a ministros de justicia real con delitos contra Cruzada. Eil mismo caso se daba también a la inversa.

"AGS, Comisatia de Cruzada, 516-240.99.7,1635.
} 


\section{Dr. Josê Antonio Benito Rodríguez}

a) Con los virreyes.

Aparte de la intervención del virrey en la predicación y administración dé la bula, la máxima autoridad política mantenía una estrecha relación con el Tribunal y los ministros de Cruzada actuando en múltiples ocasiones. Así, en un Informe del fiscal de Cruzada de Lima, Francisco Carrasco, sobre la división y erección de tribunales, confiesa con la fuerza que le da la experiencia que "importa mucho el calor del virrey" si el Tribunal procedía injustamente, el Virrey podía intervenir ${ }^{50}$. En 1687 el Subdelegado de Lima se quejaba al Consejo de Cruzada de la "poca o ninguna jurisdicción del Tribunal por la limitación de los virreyes a los tesoreros y ministros inferiores que lleva a que nadie quiera correr con el cargo",00.

A pesar de esta lamentación, lo habitual era que el virrey no interviniese en la actuación ordinaria del tribunal de Cruzada y trabajo de sus miembros, salvo en casos de actuación injusta o conflicto de competencias con otro tribunal. De la misma forma, el virrey, como hemos dicho reiteradamente, mantenia un contacto permanente con los oficiales de Cruzada, especialmente con el Comisario Subdelegado para decidir el destino de las limosnas, origen a veces de discrepancias, aunque lo normal era la armonia y buena correspondencia. Correspondencia que se basaba en el respeto y cortesia entre las partes y que comenzaba con el propio recibimiento del mandatario cuando llegaba a desempeñar el cargo. Tal lo podemos apreciar con el Tribunal de Santa Fe de Bogotá cuando a fines de 1719 delibera sobre su participación en el ceremonial de recepción del virrey Villalonga, al modo que se acostumbraba en Lima ${ }^{6 i}$.

\section{b) Obispos}

A su vez, las relaciones del Tribunal de Cruzada y sus miembros con la máxima autoridad eclesiástica del lugar fueron habitualmente también estrechas y cordiales, aunque tampoco faltaron ocasiones de tirantez y hasta de enfrentamiento. Antes de constituirse los tribunales, cuando los obispos desempeñaban mayoritariamente el cargo de Subdelegados de Cruzada apenas habia razones que enconasen la buena armonía entre los prelados y el resto de los oficiales de Cruzada. Pero a medida que la institución de la Cruzada fue afianzándose y comenzaron a ser designados como subdelegados los miembros más distinguidos de los cabildos catedralicios, las fricciones afloraron en más de una oportunidad. Este fue el caso, por ejemplo de fray Luis López de Solís, obispo de

\footnotetext{
AGS, CCI, 573. Lima, 26,5,1609.

54. de SOL.ORZANO: Politita Indiana. Madrid, 1930, Libro IV, Capitulo XXV: "Si el Tribunal de Cruzada procediera contra alguno, injustamente, puede el Virrey meter la mano para libertar al inocente: de esta opinión es el Padre Avendaños Thesaurus Indicus. Tom.1, tit.3.cap. 28 , 220 ..." n, 58

"AGS, CCJ, 561, "Estado de la Real Hacienda según el subdelegado de los Reyes" 8.I I T687?

"AGS, CCI, 580. Santa Fe. 1723.
} 


\section{CUANDO LA FE Y EL PODER MUEVEN DINERO: TRIQUIÑUELAS DEL TRIBUNAL DE CRUZADA EN INDIAS}

Quito, quien a su regreso del Concilio de Lima señala que "en Quito hallé un abușo tan grande que hará admiración a VS (el Comisario General) y por élentenderá cuáles son las cosas de las Indias y los trabajos que pasamos los obispos que estamos en ellas ${ }^{1,62}$. La denuncia formulada por el obispo se refería a que debe a que el Subdelegado General de Cruzada de Perú, Juan Velázquez, habia nombrado como Subdelegado Particular de Quito al maestreescuela de la catedral de Quito, Miguel León de Almonte, en lugar del Obispo López Solis, sin tener facultad para ello, dado que dicho nombramiento correspondia al Comisario General desde España. Tras las amenazas y penas de cárceles y excomuniones, el Obispo Luis López de Solís libera al maestreescuela y se llega a un acuerdo.

Un enfrentamiento similar se produjo en 1612 entre el obispo de 'Trujillo con el subdelegado de Cruzada, que desembocó en la mutua excomunión ${ }^{13}$. Como también, un año antes, en 1611, fue el propio obispo de Quito quien era acusado de haber instado a los religiosos de su diócesis a desobedecer al Tribunal de Cruzada ${ }^{64}$.

Sin embargo, estas desavenencias no eran corrientes. Lo habitual fue la mutua colaboración y entendimiento, pues incluso los prelados se beneficiaban económicamente de la Cruzada gracias a la concesión de parte de los fondos de las penas pecuniarias. En efecto, por disposición real, los prelados eran destinatarios de la mitad de las penas pecuniarias procedentes de multas por infracciones cometidas en la administración de la bula. Tras los primeros años en que la adjudicación era integra, a partir del 29.8.1609, debido a que las Audiencias eclesiásticas se consideraban ya establecidas y que las condenaciones iban destinadas a la guerra contra los infieles, se aplicará la mitad para los gastos de los estrados (tablados) de las dichas Audiencias y Tribunales eclesiásticos y la otra mitad para los fines señalados por el monarca ${ }^{6, \bar{T}}$.

\section{c) Inquisición}

Aunque los comisarios generales en España formaron parte en su mayoria del Consejo de la Inquisición, en Indias parece que no fue corriente que una misma persona desempeñara simultáneamente cargos en ambas instituciones. No obstante, conocemos el caso de varios ministros de Cruzada que lo fucron al mismo tiempo de la Inquisición a mediados del S.XVII. Tal fue, en 1647, Bartolomé de Estremera, comisario de la Inquisición y de Cruzada de la Villa de Salinas de Pisuerga del Valle de Mișque, Santa

\footnotetext{
AGS, CCI, 573. Qutn, 21).3.16t12.

${ }^{\circ} \mathrm{AGS}, \mathrm{CCl}, 573$. Panamá. 4.7.1612.

"AGS, CCl, 573.

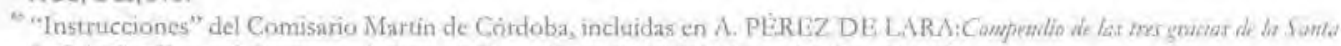

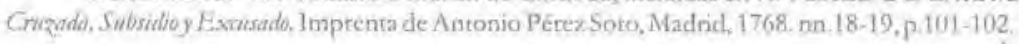




\section{Dr. Josế Antonio Benito Rodríguez}

Cruz de la Sierra $^{60}$. Un siglo después, Basilio Vicente de Quevedo, Cura y vicario de la Parroquia de Santa Bárbara de los Mogotes y antes de los pueblos de Guane, Curiti, Boyaca y San Gil. Fue Comisario de la Inquisición durante veinte años y otros tantos de tesorero primero y después de subdelegado de Cruzada $(1766-72)^{67}$. Estos dos testimonios nos llevan a pensar que en distritos pequeños el Cura Doctrinero debía acumular todas las funciones eclesiásticas y muchas veces también algunas civiles.

Al igual que el resto de las instituciones, la Inquisición recibía en cada predicación la Real Cédula, por la que se le encargaba y mandaba que "cada y cuando la presentación y predicación de la dicha Bula se fuere a hacer a esa Ciudad, salgáis al recibimiento de ella con la solemnidad y veneración que se debe a tan santa Bula, $y$ favorezcáis y ayudéis a los tesoreros, predicadores y ministros que en la predicación y cobranza de ella entendieren para que libremente y con todo favor puedan ejercer sus cargos y oficios: que en ello placer y servicio recibiré". Se les insistía también en inhibirse en el fuero propio de Cruzada y que no se entrometiesen en su actividad especifica ${ }^{\text {(ST }}$.

Creo que las relaciones entre los tribunales de la Inquisición y de Cruzada discurrieron por cauces normales, salvo en algunos casos aislados y que se producen sobre todo a lo largo del S. XVIII" ${ }^{10}$, Por ejemplo, en 1725, se produjo en Huamanga un luctuoso suceso que enfrentó a ambos tribunales como consecuencia de la decisión adoptada por el inquisidor juan de Dios Lovatón de acusar y atormentar a una india por hechicera hasta causarle la muerte y embargar los bienes a algunos de los indios de su doctrina, resultando inocentes ${ }^{70}$.

Otro caso de confrontación entre ambos tribunales se produjo doce años más tarde en México con motivo de los autos seguidos por el de Cruzada contra los bienes de D. Agustín López de Valdés, quien presuntamente debia 1.350 pesos como poderhabiente del tesorero de la Bula del obispado de Yucatán, asi como otros 21 pesos más de mandas forzosas y penas pecuniarias. El 26.6.1737 se procedió contra șus bienes, refugiándose en el convento de S. Juan de Dios"

Caso parecido tuvo lugar en el Cuzco en 1735 cuando el Tribunal de la Inquisición de dicha ciudad impidió el cobro de lo adeudado a Cruzada por Alonso Marcotegui,

\footnotetext{
AGI, Chareas, 93,6.

AGS, CCI, 567. Autor del tibro "Pensimiennos y noticias escogidas para utilidad de los curas" 5,XVII. Biblioreca del AOt di Sevilha. Basihio Viceote de Quevedo, Tesorero de Mogotes, en 1743.

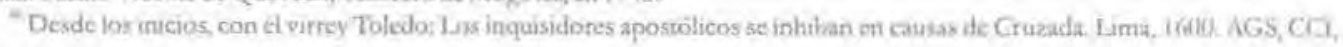
573.

"Registramos para I602 la comperencia de junsdicaòn del subdelegado de Cruzada cinquisidores por el Maeruacuela tle Thaxcala: AGI, México, 25.

AGS, CCI, 584. Madrind 10.5.1730.

'AGS, CCI, 579. 18.7.1739. Competencia con el Consejo de Ioquistción pana el conecarmientón de una causa conma Agustín
} 


\section{CUANDO LA FE Y EL PODER MUEVEN DINERO: TRIQUIÑUELAS DEL. TRIBUNAL DE CRUZADA EN INDIAS}

comisario de Inquisición, cura de la doctrina de Quiquijana en Cuzco, de haber celebrado en la capilla de Nuestra Señora del Cabildo sin abonar el importe de la composición desde 1709 con el pretexto de ser comisario del Santo Oficio ${ }^{72}$.

\section{d) Contaduría de cuentas}

Cuando no se habian constituido los Tribunales de Cruzada en Indias, los ministros encargados de la administración de la bula eran los Oficiales Reales o cualquier funcionario civil o eclesiástico de la confianza del Consejo de Cruzada. Pero al crearse los Tribunales de Cuentas en ocasiones pasaron a desempeñar dicha función contadores de estos tribunales. Las relaciones entre ambos tribunales fueron generalmente buenas. Sin embargo, una Real Cédula de 1616 al disponer las cuentas de Cruzada fuesen tomadas conjuntamente por el contador de este Tribunal y uno del de Cuentas, evitando recurrir al Consejo de Cruzada en España para el finiquito originó cierta tensión ${ }^{73}$. El problema se acentuó por una cuestión de precedencia, cuando se otorgó prioridad en el asiento al contador de Cruzada frente al parecer del Tribunal de Cuentas, que forzará al Consejo de Indias a darle la razón.

Asimismo, las relaciones con los Oficiales Reales eran frecuentes, no sólo por el hecho de que alguno de ellos se ocupara de la administración de los ingresos producidos por la predicación de la bula, sino también porque estaban obligados a desempeñar otros cometidos. Así, por Real Cédula de 1635, los Oficiales de la Real Hacienda debían dar despachos a petición del Tribunal de Cruzada de Lima sobre caudales que administraba el propio tribunal ${ }^{74}$. Parecida disposición reiterará una Real Cédula de 1695 sobre el mismo particular, ordenando a virreyes, "audiencias y demás tribunales" que no impidiesen le curso de los negocios del fisco de la Santa Cruzada ${ }^{75}$. A este respecto, J. de Solórzano señala al hablar de la relación entre los Oficiales Reales y los Subdelegados de Cruzada: "Ios subdelegados deben tratar a los Oficiales Reales en la forma y estilo que tratan a los contadores de cuentas"

\footnotetext{
Lôpez de Valdés. $\Lambda$ HN, Consejos, 2623, 2625

${ }^{12} \mathrm{AGS}, \mathrm{CCI}, 579$. Madrid, 15.4 .1739 .

AGS, CCI, 576. Real Cedula de 25,1.1616, que las cuentas de Cruzada las tome G. de la Maza y el contador del Tribural de Contaduria, Alonso Martinez de Pastrana. Sobre el Tribural de Cuentas, vénse el estudio de R. ESCOBEDO: Canerol fiseal en al virremato periano. El Tribumal de Cuentas, Albambra, Madrid 1986.

"L. RUBIO Y MORINNO: Inventario General de Regisira Cedidarios. CoDoin V. Compañia Iberoamericana de Publicaciones, Madrid 1928, 5-XI-1635, nn, 1, 17,43,139,312.

A. MURO OREJON: MURO ORLJON, A. Cedulario amerane del S.XVTHI (1680-1800). 3 tomas, Escucla de Estudios Hispanoamericanos, Sevilla, 1956. p.540-1,

"Polituoi.-A. I ibro IV, Capitulo XXV, n.46
} 


\section{e) Universidad}

También fueron frecuentes las relaciones entre la Cruzada y el mundo universitario. No en balde, varios de los ministros de Cruzada, especialmente los subdelegados, como Juan Velázquez, etan profesores universitarios. Igual cargo ostentó en el incipiente tribunal de Cruzada en Durango, Salvador Becerra y Zárate, canónigo de la Santa Iglesia de la ciudad de Durango, reino de la Nueva Vizcaya, catedrático de la Real Universidad de México y abogado de la Real Audiencia, y de quien conocemos el Memorial para, solicitar dicho cargo de subdelegado de Cruzada de Durango, en mayo de $1738^{71}$. Otros aspiraron a desempeñar dicho cargo sin conseguirlo.

Aun cuanda la correspondencia entre ambas insutuciones fue correcta, no quita para que a veces surgieran motivos de conflicto entre la Santa Cruzada y algunos miembros de los claustros universitarios. Por ejemplo, en 1600, el rector de la Universidad de Lima, Dr. Francisco de León, fue acusado y encarcelado por haber proferido palabras injuriosas contra la Cruzada ${ }^{78}$. Dos años más tarde, tambiên en Lima, fue encarcelado un catedrático de Universidad oír haber incurrido en desacato hacia contra la Cruzada durante el acto de defensa de una tesis doctoral en la iglesia Caredral".

\section{INCIDENCIAS DEL TRIBUNAL.}

Después de estudiar la fisonomía y la dinámica del Tribunal de Cruzada, paso a fijarme brevemente en alguna de las pulsaciones captadas que alteraron su ritmo habitual. Preferencias y rechazos, cumbres y baches.. en la longeva vida de esta institución.

Dentro de una institución y detrás de cada actividad hay personas responsables que, lógicamente, tienen una forma de ser, un temperamento y comportamiento, con sus virtudes, pero también con sus defectos. Esto mismo sucede en el Tribunal de Cruzada, donde comprobamos atrasos en la formación de cuentas por parte de tesoreros y contadores, conflictos motivados por incumplimiento de las competencias de cada cargo, fraudes y embargos por ambición o falta de transpatencia en el desempeño del cargo... Precisamente es la distinta diligencia puesta en el desempeño del cargo la razón

\footnotetext{
AGS, CCT, 579 .

"AGS, CCl, 573 .

${ }^{7}$ NGS, CCI, 573, "Estando ahora dos meses esta universidad en la igiesta catedral dando grado de doctor y habiendo ei cque el dijo el vejamen. entre otras comparaciones una en desacaro de la Santa Cruzada $\varepsilon$ indigsudasi de ella y del fugar donde se difio, el comisano le mandó prender después de haber acabado y estandá en el acto el oidor Gíménez de Montalvo le dijo que qué jurnsícciôn tenia para prenderle Se comurnicó al viertey que reuaido con el contador, eomusatio y asespr decerminaron fueran presos el recitunte del vejamen y ei doctor que le huzo y el rector que le vikitó y enmendó, de que Monialio mostró tanto sernumiento por la prenda que habia metidn que hiza lo posible para liberacle".
} 


\section{CUANDO LA FE Y EL PODER MUEVEN DINERO: TRIQUIÑUELAS DEL TRIBUNAL DE CRUZADA EN INDIAS}

que atribuye el tesorero de Cruzada, José Sánchez de Miranda, para que en Quito sólo le quedasen pendientes de recabar 8.399 pesos - "nada en comparación de los 40.000 pesos de Cuzco en 1726"- (debido al) "cuidado que se tiene en este Tribunal para la correspondencia de los chasquis con el Comisario Subdelegado que reside en dicha ciudad del Cuzco y con el Sr.Obispo para que celen a los curas y doctrineros el que saquen todos sus feligreses la Santa Bula en el bienio de cada predicación" ${ }^{\text {"80 }}$.

\section{a. Pleitos}

Dentro de la gran complejidad de relaciones establecidas por los tribunales de Cruzada no faltan los numerosos pleitos. Por ejemplo, en relación con el mundo universitario el pleito criminal formado contra el rector Francisco de León en 1600. Seis años antes, en 1594, también en Lima, lo promueve el tesorero general de Cruzada, Miguel Sánchez de la Parra, contra sus fiadores por no satisfacer el alcance convenido de la segunda predicación ${ }^{81}$. En otras situaciones, son los organismos los que colisionan, como en el litigio de 1619 en México entre el cabildo, Ias justicias y los regidores contra el tesorero de Cruzada de México, Francisco de la Torre, por un motivo característico de la sociedad indiana: la precedencia de asiento, voz y voto ${ }^{82}$. A su vez, en 1627 , F. Núñez Melián, tesorero de Cruzada en Cuba, mantiene otro pleito con el fiscal, el prior y cónsules de Sevilla y demás interesados en la plata de Matacumbe (Barlovento), por no estar claro el asunto acerca de la pertenencia del preciado metal entre los bandos en litigio ${ }^{8.3}$. No faltaron tampoco los pleitos movidos por los Oficiales Reales, como en el caso de J.M. de Anaya y F. de la Guerra, tesorero y factor de las Cajas Reales de Lima, ante su negativa a dejar sacar ciertas partidas al Comisario J. Velázquez ${ }^{84}$. Otras veces, el motivo arranca de la imposición de multas injustas ${ }^{85}$, como sucede en 1668, en que Antonio del Castillo Camargo, gran canciller de Cruzada, a una con el fiscal, reclaman a la Casa de Contratación la devolución de la multa.

Entre las denuncias que frecuentemente presentaban los fiscales figuraban las causadas por fraudes en las ventas de productos básicos como el vino o el cacao ${ }^{87}$. Pero,

\footnotetext{
${ }^{n 0}$ AGS, CCI, 564.1.ma, 22.10.1734.

"AGS, CCI, 574.

"AGI, Escribania, $168 \mathrm{~A}$.

"AGI, Escribania, 1022 C.

"AGI, Escribania, 502 A. Tambiên, en 1724, AGI, Esscribania, 340 B. Pleitos de Oficiales Réales de Guaremala con losé de Gálvez Corral,contador mayor de Cruzada sobre preeminencras.

"AGI, Escribania, $1089 \mathrm{C}$.

"AGI, Escribania, 1037 C. Pleitos del fiscal con Antonuo del Castillo Camargo, canciller de Cruzada, sobre paga de 33.712 reales de remisiones de vino en 1672 ,

"AGI, Escribania, 176B. 1673, Pleito dej fiscal con Antonio de Azucena, Felipe de Barrada y Antonio Maldonado, tesorero de Cruzada de Mérida, por feaude en la venta de unas Eancgas de cacao.
} 


\section{Dr. Josẻ Antonio Benito Rodriguez}

sin lugar a dudas, uno de los pléitos más sonados lo protagonizó en 1719, en Cartagena de Indias, el Comisario Mario Betancour, el cual parece ser que llegó a fulminar la excomuniôn contra su prelado. El obispo arremetió contra él y consiguieron echarlo de la Sala de Cruzada a "grandes empellones" entre Juan Pingarrany Diego Pérez. Se llegó a meter en prisión al Comisario Subdelegado, embargándole toda la documentación y el mismo archivo del Tribunal de Santa Cruzada ${ }^{\text {"A. }}$. En la misma fecha y lugar, hay testimonio de autos obrados por Luis de Quevedo, deán de la Catedral y Comisario Subdelegado, por haber quitado el anterior comisario subdelegado, Mario Betancour, los despachos originales del Comisario General de Cruzada y del Arzobispo de Santa Fe a los ministros de Cruzada que los iban a notificar. El subdelegado Betancour llegó a tirar del espadín, siendo ayudado por su hermano Francisco y el personal de servicio ${ }^{k 9}$.

Veinte años más tarde, hacia 1742, la ciudad de Cuzco pudo contemplar otro reñido pleito que enfrentó al tesorero Manuel Jiménez Lobatón y Costilla y al cura Felipe de Veneres. Al tesorero no le iba muy bien, pues "he determinado salir de este cuidado por emprender con toda libertad otros designios que me sean más favorables sin tanto subsidio por la penalidad que he experimentado en la recaudación de la limosna de la Santa Bula, de cuyo importe todavía se me está debiendo ${ }^{9,9 \%}$. El tesorero Jiménez Lobatón solicitó excomunión y citación en la tablilla para el párroco de Paucartambo, Felipe de Veneres, por no pagatle 1.915 pesos y 306 pesos a su padre Nicolás Jiménez (antiguo tesorero), pues "llegado el caso de requerirle y haberse de actuar las diligencias convenientes de su cobranza, las embarazó e impidió presentando un despacho de Su Señoria inhibitorio en que se le concedió por Su Señoría que los enteros de las cantidades que debiese de la limosna de la Bula las hubiese de hacer en la Tesorería General". Se requiere al General Sebastián Marqués Escudero, corregidor del Real Asiento de Paucartambo, para que exhiba todo lo que pertenece a dicho cura, o de lo contrario se le embargarian los bienes. El litigio concluyó comisionando al clérigo José Simón de Quintanilla con diligencias para concluir el caso, pues en otro testimonio de autos el propio cura Felipe Veneres denunciaba al tesoreto porque:

$\left.1^{\circ}\right)$ En su doctrina se habian tepartido 4.457 bulas en la última predicación, cuando lo habitual era 3.384 , y exiǵa la limosna íntegra sin admitir la devolución de bula alguna que sobrase, lo que era contratio a la ley que ordenaba que los comisarios de Cruzada "no consientan ni apremien a ningưn indio a que las reciba ni aún vaya a los sermones contra su voluntad", En lugar de esto se les habia obligado a sacarla por

\footnotetext{
"AGS, CCI, 580.

$" \mathrm{AGS}, \mathrm{CCI}, 580$.

*AGS, CCI, 576. Carta de 11-12-1742 al Comisario Subdelegado del Tribunal de Cruzada de Cuzco.

"Recopilación... [22]. Libro 1, Título 20, Ley X.
} 


\section{CUANDO LA FE Y EL PODER MUEVEN DINERO: TRIQUIÑUELAS DEL TRIBUNAL DE CRUZADA EN INOIAS}

duplicado y hasta por triplicado.

$\left.2^{\circ}\right)$ Además, nada más predicada la bula quería cobrarla, sin esperar al fin de la predicación. En consecuencia, Felipe Veneres, exigía la devolución de las bulas sobrantes y que el tesorero fuera obligado a aceptarlas, exonerándole de las vejaciones que cometían contra su persona el comisario y tesorero de aquella ciudad por el hecho de haber sido familiar del Ilustrísimo D. Juan de Sarricolea, obispo de aquella ciudad, quien había informado y descargado su animadversión sobre este asunto de la bula ${ }^{\text {biz }}$.

\section{b. Fraudes}

Aun sin caer en las ingeniosas tretas de los buleros de la Península Ibérica y de las que el mismo Consejo de Cruzaba alertaba a los fieles ${ }^{13}$, los territorios ultramarinos sc vieron sometidos también a la acción fraudulenta de algunos de los ministros de Cruzada, particularmente de los tesoreros receptores o recaudadores.

Los fraudes más corrientes consistian en sacar a los fieles, en concepto de limosna, prendas-cuando no pagaban en moneda- por más valor que la cantidad de maravedís en que se tasaban las bulas, vendiendo dichas prendas a bajo precio. Hubo receptores que, además, comerciaban con el producto de la bula, empleando el dinero en frutos de la tierra, que embarcaban con empleos de mayor cantidad para eximirlos del pago de la alcabala $^{\text {wt }}$. Otras veces, repartian bulas caducadas de otras predicaciones e, incluso, llegaron a cobrar dinero por sumarios o cartas impresas que hacian pasar por bulas, como sucedió en 1743 en la ciudad de Caracas ${ }^{95}$.

Aunque las actuaciones fraudulentas solian provenir de los tesoreros ${ }^{9 / 6}$, no quedaban exentos otros cargos como el de notario de Lima, Alonso Ramos Cervantes", a comienzos del siglo XVII. Dos síglos después, en 1803, también nos hemos encontrado que otro notario, Luis Camargo, es acusado de malversación de los fondos del Tribunal de Cruzada de Valladolid ${ }^{3 / 8}$. Y hasta los mismos clérigos, que gozaban de tan buena reputación en Indias, cayeron en tales abusos; así le sucedió, en 1667, a Luis Escobar, a quien se formó proceso criminal por engañar a una esclava mulata que le

\footnotetext{
${ }^{n} \mathrm{AGS}, \mathrm{CCl}, 576,28.4 .174 \mathrm{~L}$

$"$ AGS, PR, 1862: "Lo que se debe tratar para la publicación de la Bula en Indias"(sin fecha), Parecen tomados de los avisos dadon desçe España a la hora de recabat intormaciôn para traspasarla a las Indias, anies de 1573.

"M.). AYALA: Dicaionario... [27], Voz. "Cruzada", n.18. Real Cédula de 6 de diciembre de 1702 dada en Buenos Aires.

"AGS, CCI, 578.

"AHN, Consejos, Li2615.

"AGS, CC1, 573. Sus excesos y fraudes fueron descubiertos por la acción conjunta del Contador G. de la Maza y el Subdelepado I. Velïzquez.

"AGN, México, 417 .
} 


\section{Dr. José Antonio Benito Rodriguez}

había pedido dos bulas de tasa de a peso para vivos entregándole dos bulas de tasa de a dos reales de vivos".

En otra ocasión nos encontramos con que el tesorero de Comayagua, Francisco Javier López Rebollo, en 1735, pide justicia y que se tome juramento a Francisco de la Peñuela acerca de las bulas que le entrégó para llevârselas a José Mendoza, responsable de su administración. El tesorero López Rebollo asegura haberle entregado bulas por valor de 205 pesos, 3 reales y 3 cuartos, y mientras que Peñuela sólo admitía de su cargo 85 patacones, por lo que al tesorero le faltaban en el arca de 300 pesos del expendio de dichas bulas. Por todo ello, acababa solicitando poder cobrar tal cantidad y excomunión de los culpables ${ }^{110}$.

Para corregir abusos, como los de los ejemplos citados, se arbitraton medidas preventivas con advertencias sobre la experiencia de los echacuervos o tesoreros buleros sin escrúpulos, a bien con la adopción de medidas muy concretas, como la de que fuesen los Consejos los que nombrasen los tesoreros-"cogedores" o recaudadores ${ }^{\text {iot }}$.

\section{c. Embargos}

Asimismo, con el fin de corregir los abusos y fraudes contra la limosna de Cruzada se tomaron medidas contundentes y extremas, como fueron el embargo, la cárcel y la excomunión, para asegurar el cobro de la Bula. Abundan los tesoreros embargados, como veremos a continuación.

Por ejemplo, en 1597, se produce el secuestro de los bienes del tesorero de Cruzada de Perú, J. Beltrán de Aparicio, por deuda de 400,000 pesos ${ }^{\text {"1:? }}$.

1638. Querella de Mateo Barroso contra F. Muñoz Catalán para que se lleve a efecto el embargo de sus bienes ole pague la deuda contraída con Luis Pérez, tesorero de Cruzada de México ${ }^{103}$.

1648. El alcalde ordinario de Riobamba, Martin de Eyzaguirre, y un hermano suyo, procurador, no permítieron al receptor de Cruzada que fuese acompañando al estandarte. Este se quejó ante el comisario subdelegado Ventura Falconi. El alcalde les menospreció por encontrar respaldo en el Presidente de la Audiencia de Quito, Martín de Arriola, compatriota suyo, con gran escándalo en la procesión. Juzgado, fue apresado y sc le embargaron los bienes

\footnotetext{
AGS, CCI, 583, Triburial de Cruzada. México, 2.4.1667. Fdo Nicolás del Puerto Dòn Fęo Calderon Romero, Don Juan Manuel de Escalante y Mendoza.

AGS, CCl, 567.

AGS, $\mathrm{CCI}, 578$

* AGS, Ca, 573. Dos años después siguen con el embargo 3.11.1600 tama. Diligencias contra los bienes de lias fídrures mucrtos del tesoreto f. Beltrin

AGN, México, 27,

in $\mathrm{AGS}, \mathrm{CCl}_{4}, 572$
} 


\section{CUANDO LA FE Y EL PODER MUEVEN DINERO: TRIQUIÑUELAS DEL TRIBUNAL DE CRUZADA EN INDIAS}

1705. Embargo de los bienes de Juan Antonio de Porras y de Domingo Gutiérrez de Villavicencio, hijo y yerno, respectivamente, del tesorero general de Cruzada de Santa Fe, Juan de Porras, por no haber satisfecho éste el alcance de 1.510 pesos que declaró deber pagar por impago de la limosna de Cruzada ${ }^{105}$.

1729. El tesorero de Huamanga, Benito Pérez, es condenado por ilícito comercio de ropa francesa. Le multaron con 4.000 pesos, a los que no puede hacer frente. Y "con estas quiebras hallándose el referido tesorero sin caudal para pagar lo que debía de las predicaciones de su cargo, se apesadumbró y murió" ${ }^{100}$. El juez Jorge Cugurra embargó sus bienes para cubrir la deuda contraída con la Cruzada.

1729. El vicario de Yungay embargó los bienes del tesorero Juan Bautista Robles por no haber cumplido en fundar una capilla que dejó mandada su padre, habiendo atropellado el fuero de Cruzada ${ }^{107}$.

1738. En la Contaduría de Lima se recogieron los autos de embargo en los bienes muebles y casa del tesorero de Arica, Diego Diaz González, además de un navía que tenía en el Puerto del Callao. Tras formarse concurso de acreedores al que se opuso su mujer por su dote y para que en la dilación de la causa no se menoscabase y consumiese la mayor parte de su valor, se remató en precio y cantidad de 9.600 pesos ${ }^{108}$.

\section{d. Prisión}

Pero no sólo fueron frecuentes los embargos por deudas, sino que también abundaron los casos de los hombres de Cruzada que terminaron en la cárcel, principalmente tesoreros. Las causas suelen obedecer a no satisfacer a su debido tiempo los alcances de la limosna, como le sucedió a Alonso Benitez, tesoreto de Tenza en 1732, o Pedro de Torres, también tesorero en Santiago de Chile en 1709. En ocasiones, como en el caso del notario de Cruzada de Lima, Alonso Ramos Cervantes, se debió a la falta de claridad en las cuentas. Pero hubo circunstancias en que la pena de prisión fue impuesta por motivos mucho más insignificantes, como al comisario de Cartagena, Simón Chacón, a quien se encarceló por no asistir a las "letanias de mayo con tropelía $y_{x}$ sin embargo, estar en despacho ${ }^{\text {,10\% }}$

\footnotetext{
${ }^{\text {ias }}$ AGS, CCI, 566. En uno de los informes, para justificar el impago de la limosna, habla "del viaje de Popayán, el largo destierro, los mis. enemigos, mi mucha pobreza". Después de muchas averiguaciones el fiscal ordena que debe abonar toda antes del 16,11.1706. De no pagarlo se le amenaza con la pública excomunión. Sele encarcela y embargan sus bienes.

- El 23.14.1705, el fiscal, en vista de los autos, dicta sentencia condenatora sobte los hijos y herederos, especialmente con su hijo Jusn Antonio Porras y su yerno Domingo Gutiérrez de Villavicencio EI 18.6.1708 El Fiscal ardena se proceda a cobrar los alcances pendientes del tesorero Juan de Porras.

${ }^{10} \mathrm{AGS}_{3} \mathrm{CCl}, 562$.

(10" $\mathrm{AGS}, \mathrm{CCl}, 584$

AGS, CCI, 563

AGS, CCI, 584 .
} 
Por la documentación hallada, parece que el tribunal actuó con firmeza, sin respetar cargo por superior que fuese, pero al mismo tiempo con flexibilidad, como nós revela el hecho de soltar al tesorero Alonso Benitez por pagar la cantidad adeudada de 84 pesos o ni siquiera encarcelar a Pedro Miguel de Barros por "estar mal de estómago".

\section{e. Excomuniones}

Esta pena espiritual era el peor de los castigos que se podía imponer en una época impregnada por la religión. No obstante, en diversas ocasiones nos encontramos con que esta privación fue aplicada por distintas causas. Así, el 15 de octubre de 1600, en Lima, se amenazó con la excomunión por la compra de esclavos negros sin licencia a la viuda del embargado tesorero de Perú, Juan Beltrản de Aparicio. En la misma fecha se excomulgó al escribano de Lima, Nicolás de Salazar, por no entregar en tiempo señalado al Secretario del Tribunal de Cruzada un escrito pedido por Martín de Briviesca Roldán, Oficial Real ${ }^{110}$. A su vez, el Comisario subdelegado de Cartagena, Francisco de Yarza, deán de la catedral, excomulgó a los Oficiales Reales, F. de Rebolledo y Juan de la Huerta, por deudas, notificando que "sean puestos en la tablilla para que llegue a noticia de todos y que de ella ninguna persona sea osado a quitarlos so pena de excomunión mayor y 100 pesos"; alegarán que no son ellos los herederos de los deudores y que se excomulgue a los verdaderos ${ }^{11}$.

Finalmente, en 1620, nos encontramos con una imposición de excomunión a toda una población, como la de Xegua, Santa Fe, por no acudir a la predicación de la bula ${ }^{112}$. Y el 5 de octubre de 1698, ante la invasión de la plaza por los franceses y la exhortación a que acudan todas las fuerzas vivas de Cartagena a la publicación y recibimiento de la Bula, el subdelegado Nicolás de Barros excomulgó a los superiores de la Orden de San Agustín por desobedecer el llamamiento ${ }^{113}$.

\section{Conclusión:}

G. Escalona, clásico de la Hacienda Indiana, nos ayuda a calibrar el gran alcance de la Bula desde la atalaya de su Gazopbilacium Regium Perubicum de 1775:

"Lo procedido de la limosna de esta santa bula es una de las rentas más considerables que Su Majestad tiene en las Indias; $y$ la diferencia que en su cobro hay de ella a las demás es que cada uno es cobrador de sí mismo, porque el celo

\footnotetext{
${ }^{16} \mathrm{AGS}, \mathrm{CCI}, 573$

$11 \mathrm{AGS}, \mathrm{CCl}, 568$.

"AGS, CCI, 568 .

1"' $\mathrm{AGS}_{\mathrm{C}} \mathrm{CCl}, 568$.
} 
Mapa de las localidades morosas del Perú

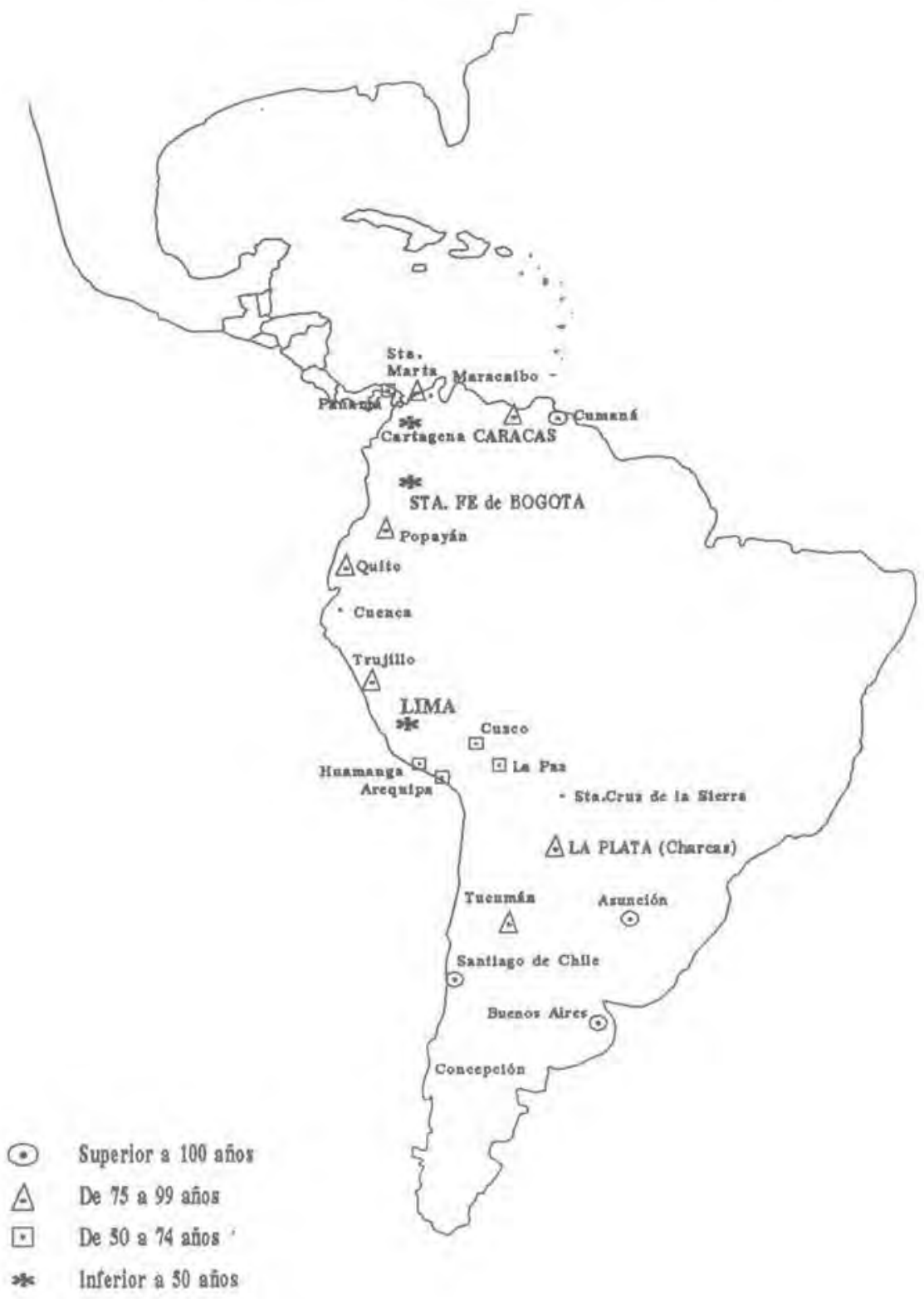

Atrasos en las cuentas del Virreinato del Perú en 1711 
cristiano de gozar de las gracias e indulgencias concedidas a los fieles por los sumos pontifices, interpela y convida a esta voluntaria contribución. Habiendo concedido a su majestad la santidad de Julio II, la Bula, para los reinos de Castilla, después se extendió su concesión por la santidad de Gregorio XIII: para los estados de las Indias, como parte y porción de aquéllos y se ha ido continuando hasta ahora por tiempo de seis predicaciones cada concesión y por ser para gastos que se han hecho, $y$ hacen en la defensa de la iglesia contra sus enemigos ${ }^{\text {nit }}$,

Si tenemos en cuenta dos de sus notas, la exclusividad, por la que su aplicación suspendía automáticamente todo tipo de jubileos y gracias pontificias, junto a la universalidad, ya que abarcaba a todos los súbditos de la monarquía mayores de doce años y residentes en cualquier parte del territorio peninsular o ultramarino (además de los difuntos), podemos concluir con la agudeza, no exenta de su peculiar ironía, del historiador P. Mariana, al analizar la imbricación de la Bula con la campaña granadina:

"Sixto [IV...] concedió así mismo la cruzada a todos los que, a su costa, fuesen a la guerra [o], por lo menos ayudasen con ciertos maravedís para los gastos, lo cual se tornó a conceder el tercer año adelante, y desde principio, ya todos los años, se recoge por este medio gran dinero para los gastos reales, camino que inventaron en aquella sazón personas de ingenio ${ }^{2115}$.

Ciertamente, hay sutileza, creatividad, triquiñuelas, de "personas de ingenio" ${ }^{\prime}$ para asegurar tan preciada limosna.

Dr. José Antonio Benito Rodriguez

Dr. en Historia de América

"' G, ESCALONA: Garqpbilacium Regiom Ponhioum Libro II, Parte II, Capitulo XXXII, p.243 Madrad 1775, Tipografta Blas, Biblioteca Nacionat de Madrid, Sección "Raros" N" 17.982 .5$.

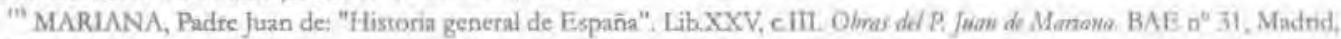
1950. Torse $11, \mathrm{p} .215$ 